\title{
Alpha-Mangostin Suppresses the Metastasis of Human Renal Carcinoma Cells by Targeting MEK/ERK Expression and MMP-9 Transcription Activity
}

\author{
Chien-Min Chen ${ }^{a, b}$ Shu-Ching Hsieh chia-Liang Lin ${ }^{d} \quad$ Yu-Syun Lin ${ }^{d}$ \\ Jen-Pi Tsai ${ }^{, f} \quad$ Yi-Hsien Hsieh ${ }^{d, g, h}$
}

\begin{abstract}
aDivision of Neurosurgery, Department of Surgery, Changhua Christian Hospital, Changhua, 'bSchool of Medicine, Kaohsiung Medical University, Kaohsiung, 'School of Medical Laboratory and Biotechnology, Chung Shan Medical University, Taichung, 'Institute of Biochemistry, Microbiology and Immunology, Chung Shan Medical University, Taichung, eSchool of Medicine, Tzu Chi University, Hualien, ${ }^{f}$ Division of Nephrology, Department of Internal Medicine, Dalin Tzu Chi Hospital, Buddhist Tzu Chi Medical Foundation, Chiayi, 9Department of Biochemistry, School of Medicine, Chung Shan Medical University,

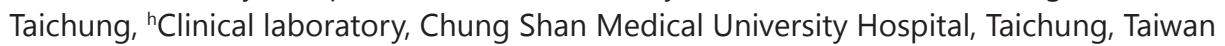

\section{Key Words}

$\alpha$-Mangostin $\cdot$ Renal carcinoma cells $\cdot$ Migration $\cdot$ Invasion $\cdot$ MMP-9

\begin{abstract}
Background/Aims: $\alpha$-mangostin has anti-carcinogenic effects against several cancers. We investigated the molecular mechanism of this compound on the metastasis of human renal carcinoma cells. Methods: Cell viability was measured using the MTT assay, and cell cycle distribution using flow cytometry. A Matrigel-based assay was used to measure in vitro cell migration and invasion. MAPK-related proteins and matrix metalloproteinase (MMP)- 9 and MMP-2 expression were measured by western blotting, and MMP2/-9 activities were determined by gelatin zymography. RT-qPCR and a luciferase assay were used to examine the transcriptional activity of MMP-9. Results: $\alpha$-mangostin inhibited the migration and invasion of RCC cells in a dose-dependent manner, but had no evident cytotoxic effects. Treatment of 786-O cells with $\alpha$-mangostin inhibited activation of MEK and ERK. Treatment with a specific MEK inhibitor (U0126) enhanced the inhibitory effects of $\alpha$-mangostin on cell migration and invasion, and the phosphorylation of ERK and MEK. Moreover, $\alpha$-mangostin inhibited the expression of the MMP-9 mRNA levels as well as the activity of MMP-9 promoter, and these suppressive effects were further enhanced by U0126. Conclusions: Our results suggest that $\alpha$-mangostin suppresses cell migration and invasion via MEK/ERK/MMP9 pathway, and might be a promising anti-metastatic agent against human renal cell carcinoma.
\end{abstract}




\section{Cellular Physiology Cell Physiol Biochem 2017;44:1460-1470 and Biochemistry Published online: December 01, 2017 \begin{tabular}{l|l} 
DOI: 10.1159/000485582 2017 The Author(s). Published by S. Karger AG, Basel \\
www.karger.com/cpb
\end{tabular} \\ Chen et al.: Anti-Metastasis Effect of $\alpha$-Mangostin in Human Renal Carcinoma Cells}

\section{Introduction}

Renal cell carcinoma (RCC) is the most lethal genitourinary cancer, and patients with metastatic RCC have poor overall survival times [1]. Although patients who have RCC but no evidence of metastasis may be treated locally with partial or radical nephrectomy, those with metastatic RCC require cytoreductive nephrectomy followed by newly developed methods, including immunotherapy, anti-angiogenic agents, and mTOR inhibitors, to improve survival time [2]. However, these therapies have limited efficacy when RCC is diagnosed at an advanced stage or if there are distant metastases, because of tumor resistance to chemotherapy, radiotherapy, and hormone therapy [3, 4]. Despite recent encouraging reports that targeted therapy with inhibitors of tyrosine kinase and mTOR can reduce mortality, the prognosis for patients with advanced stage or distant metastases remains dismal [5].

Chemoprevention of cancer by usage of dietary bioactive compounds could potentially reverse, suppress, or prevent cancer progression [6]. We recently found that nimbolide, a tetranortriterpenoid isolated from the leaves and flowers of the neem tree (Azadirachta indica), can inhibit the growth of RCC [7]. $\alpha$-mangostin (Fig. 1A), a natural xanthone isolated from the pericarps of mangosteen (Garcinia mangostma L), known as the "queen of fruits", also has in vitro and in vivo activities against various human malignant cells, in addition to well-known anti-inflammatory, anti-oxidant, and anti-bacterial effects [8, 9] . $\alpha$-mangostin appears to exert its anti-tumor effects by distinct mechanisms in different types of cancer cells; it induces cell cycle arrest and increases the levels of reactive oxygen species in breast cancer cells [10], it induces apoptosis in prostate cancer cells [11], and it inhibits proliferation and promotes apoptosis in gastric cancer cells [12].

One of the primary reasons for the failure of RCC treatments is that patients with advanced RCC often develop resistance to anti-cancer agents [13]. The matrix metalloproteinases (MMPs), crucial proteolytic proteinases that allow malignant cells to access the vasculature, are a family of zinc-dependent endopeptidases with broad substrate specificities for a variety of extracellular matrix (ECM) and basement membrane proteins [14]. Aberrant regulation of the MMPs disrupts normal cellular interactions, and leads to lysis of the ECM and breaching of the basement membrane, thereby allowing malignant cells to migrate and invade distant tissues [15]. Previous studies of RCC indicated that increased expression of MMP-9 and ERK were associated with the severity of RCC, tumor size, TNM stage, invasion, distant metastasis, and cancer-specific survival $[15,16]$. Various intracellular upstream signaling cascades, particularly the mitogen activated protein kinase (MAPK) pathways, regulate the production of MMP-2 and MMP-9. The major components of the MAPK pathways, the ERK, JNK, and p38 MAPK pathways, regulate cell migration, invasion, proliferation, survival, and apoptosis following different cellular signals $[17,18]$. $\alpha$-mangostin can modulate tumor migration and invasion by down-regulating MMP-2, MMP-9, and urokinase-type plasminogen activator $(\mu \mathrm{PA})$ through the $\alpha v \beta 3$ integrin receptor and the FAK/ERK/NF- $\kappa B$ signal pathway in lung

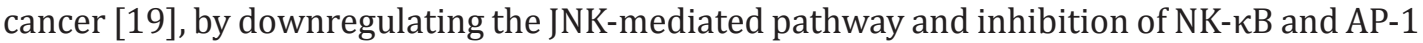
binding activity in prostate cancer [20], and by suppressing the ERK-mediated pathway and reducing $\mathrm{AP}-1$ and $\mathrm{NK}-\kappa \mathrm{B}$ binding in breast cancer [21].

It is important to develop new methods to prevent metastasis of RCC. Despite encouraging reports regarding the efficacy of new therapies for RCC, the prognosis of patients with advanced or metastatic RCC remains poor. It is noteworthy that $\alpha$-mangostin preferentially targets cancer cells, and has limited toxic effects on normal cells. Thus, $\alpha$-mangostin has potential as a new therapy for RCC that induces few adverse effects. We examined the effect of $\alpha$-mangostin on highly invasive human RCC cells and the underlying mechanism of its effect on RCC metastasis.

\section{Materials and Methods}

Cell culture

CaKi-1, ACHN, and A-498 cells were routinely cultured in MEM medium, 786-0 cells were cultured in RPMI medium, and human renal tubule HK-2 cells were cultured in DMEM-F12 medium. Each growth 


\section{Cellular Physiology Cell Physiol Biochem 2017;44:1460-1470

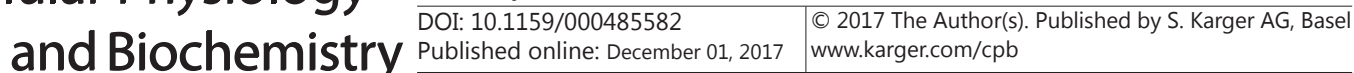 \\ Chen et al.: Anti-Metastasis Effect of $\alpha$-Mangostin in Human Renal Carcinoma Cells}

medium was supplemented with $10 \%$ fetal bovine serum (FBS), sodium pyruvate, $100 \mathrm{U} / \mathrm{mL}$ penicillin, and $100 \mu \mathrm{g} / \mathrm{mL}$ streptomycin. All cells were grown in a humidified incubator with $5 \% \mathrm{CO}_{2}$.

\section{Gelatin zymography assay}

786-0 cells were seeded in 24 well plates and treated with different concentrations of $\alpha$-mangostin for $24 \mathrm{~h}$. Then, conditioned media were collected to measure MMP-2 and MMP-9 activity. The medium was subjected to SDS-PAGE in an $8 \%$ polyacrylamide gel copolymerized with $0.08 \%$ gelatin, as previously reported [22].

\section{MTT assay}

The effect of $\alpha$-mangostin on the viability of human RCC cells was determined using the MTT assay [23]. Cells were seeded in growth medium in 24 -well plates for $24 \mathrm{~h}$, treated with different concentration of $\alpha$-mangostin for 24 and $48 \mathrm{~h}$, and then the 3-(4, 5-dimethylthiazol-2-yl)-2, 5- diphenylterazolium bromide (MTT) reagent was added for $4 \mathrm{~h}$. The formazan precipitate was dissolved in $1 \mathrm{~mL}$ isopropanol, and absorbance was measured at $570 \mathrm{~nm}$ using a microplate reader (Bio-Rad Laboratories, CA).

\section{In vitro migration and invasion assay}

Cells $\left(2 \times 10^{5}\right.$ cells/well) were plated onto $6 \mathrm{~cm}$ culture plates in medium containing $10 \% \mathrm{FBS}$, and then pre-treated with $\alpha$-mangostin $(0,4,8$, or $12 \mu \mathrm{M})$ for $24 \mathrm{~h}$. The lower compartment of polyvinylpyrrolidonefree polycarbonate filters (Millipore; 8-mm pore size) was filled with $50 \mu \mathrm{L}$ of $10 \%$ FBS medium. After incubation, the total number of migrated cells was counted following standard procedures. The in vitro invasiveness was investigated in the upper membranes that were precoated with Matrigel $(40 \mu \mathrm{L}, \mathrm{BD}$ Biosciences), as previously described [24]. The number of migrated cells was counted using an inverted microscope (Leica, $\times 200$ ). Three sets of 5 microscopic fields were counted for each sample.

\section{Western blotting}

786-0 cells were cultured in 6-cm dishes for $24 \mathrm{~h}$, and then pre-treated with $\alpha$-mangostin $(0,4,8$, or $12 \mu \mathrm{M}$ ) for $24 \mathrm{~h}$. The cells were washed with cold PBS, harvested, and total protein concentration was measured. The proteins were separated electrophoretically using a $10 \%$ SDS-polyacrylamide gel, and then transferred onto an Immobilon P PVDF membrane (Merck Millipore, Billerica, MA). The membranes were blocked in 5\% milk for $1 \mathrm{~h}$, and then incubated with primary antibodies for MMP-2, MMP-9, p-MEK, p-ERK, p-p38, p-JNK, MEK, ERK, p38, JNK, and $\beta$-actin (loading control) at $4^{\circ} \mathrm{C}$ overnight. After hybridization with an HRP-conjugated secondary antibody (Santa Cruz Technology), protein bands were visualized using a chemiluminescence detection kit (GE Healthcare, London, UK). The bands were visualized by enhanced chemiluminescence using a Luminescent Image Analyzer LAS-4000 mini (GE Healthcare).

\section{RT-qPCR assay}

Total RNA was extracted from $\alpha$-mangostin-treated cells using a High Pure RNA Tissue Kit (Roche Applied Science, Mannheim, Germany). Total RNA (1 $\mu \mathrm{g}$ ) was synthesized by reverse-transcribing total RNA using a ReverTra Ace qPCR RT Master Mix kit (TOYOBO, Japan). The qPCR was performed using a GoTaq qPCR Master Mix (Promega, MW, USA). The primers were: $\beta$-actin forward, 5'-GCACTCTTCCAGCCTTCCTTCC-3' and reverse, 5'-TCACCTTCACCGTTCCAGTTTTT-3'; MMP-9 forward, 5'-CCTGCCAGTTTCCATTCATC-3' and reverse, 5'-GCCATTCACGTCGTCCTTAT-3' (MISSION BIOTECH, Taipei, Taiwan). The PCR amplification consisted of 40 cycles at $95^{\circ} \mathrm{C}$ for $5 \mathrm{~s}$, and $58^{\circ} \mathrm{C}$ for $30 \mathrm{~s}$ after an initial denaturation step at $95^{\circ} \mathrm{C}$ for $30 \mathrm{~s}$. The results were analyzed using a standard curve-based method. The gene expression is expressed relative to endogenous GAPDH, and determination of the difference in threshold cycle (Ct) between treated and untreated cells using the $2^{-\Delta \Delta C t}$ method.

\section{MMP-9 luciferase activity assay}

Transfection of 786-0 cells with MMP-9 promoter-luciferase vectors was performed using Tuberfast transfection reagents for $24 \mathrm{~h}$, and then addition of $\alpha$-mangostin $(4,8$, or $12 \mu \mathrm{M})$ for $24 \mathrm{~h}$. Cells were washed with PBS and lysed with $50 \mu \mathrm{L}$ passive lysis buffer (Promega, Madison, WI, USA). Lysates were transferred to 96-well plates, and the luciferin substrate was added (Promega, Madison, WI). A microplate reader was used to determine luciferase activity and $\beta$-gal enzyme activity was measured with a luciferase assay kit following 
the manufacturer's instructions. Relative luciferase activity was calculated by dividing the fluorescence units of MMP-9 reporter plasmid-transfected cells by the fluorescence units of pGL3-Basic-transfected cells.

\section{Statistical analysis}

All data are expressed as means \pm standard errors. Statistical analysis was performed with GraphPad Prism (version 5). Analysis of variance (ANOVA) and an unpaired 2-tailed Student's t-test were used to determine the significance of differences.

\section{Results}

$\alpha$-mangostin does not affect cell viability or cell cycle distribution

Fig. 1A shows the structure of $\alpha$-mangostin. We initially used the MTT assay to determine the effect of this compound on cell viability (Fig. 1). The results show that it had no significant effects on the growth of normal human proximal tubule epithelial (HK-2) cells or on 4 different lines of RCC cells (786-O, A-498, CaKi, and ACHN) at the tested concentrations ( 0 to $12 \mu \mathrm{M})$ and durations ( 24 and $48 \mathrm{~h}$ ). In addition, flow cytometry analysis indicates that a 24 $\mathrm{h}$ treatment with $\alpha$-mangostin had no effect on the cell cycle distribution of A-498 and 786-0 RCC cells (Fig. 2). Based on these results, we used $\alpha$-mangostin concentrations of $2 \sim 12 \mu \mathrm{M}$ for all subsequent experiments.

\section{$\alpha$-mangostin inhibits in vitro migration and invasion of RCC cells}

We treated A-498 and 786-0 cells with different concentrations of $\alpha$-mangostin for $24 \mathrm{~h}$, and then measured in vitro migration and invasion of these cells. The results indicate that $\alpha$-mangostin significantly inhibited migration and invasion of each cell type in a concentration-dependent manner (Fig. 3). At a concentration of $12 \mu \mathrm{M}$, the percent migration and invasion of each cell type was about $20 \sim 30 \%$ of that in the controls $(0 \mu \mathrm{M})$.

Fig. 1. Effects of $\alpha$-mangostin on cell viability of RCC cells. (A) Chemical structure of $\alpha$-mangostin. (B-F) HK-2, 786-O, A-498, CaKi-1, and ACHN cells were incubated with various concentrations of $\alpha$-mangostin for 24 and $48 \mathrm{~h}$, and cell viability was determined using the MTT assay. Data are presented as means \pm SEs of at least 3 independent experiments.* indicates $\mathrm{p}<$ 0.05 and $^{* *}$ indicates $\mathrm{p}$ $<0.01$ compared with the untreated control $(0 \mu \mathrm{M})$.
A

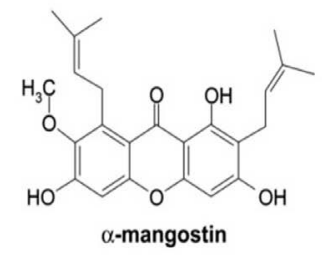

C

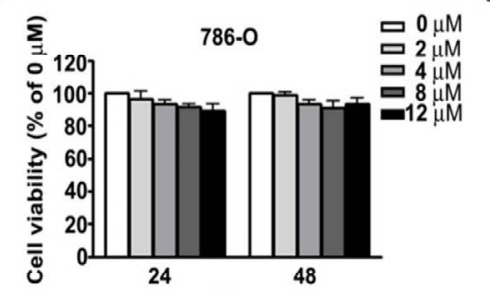

(h)

E

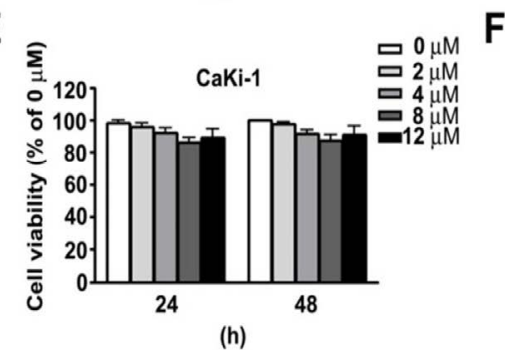

B

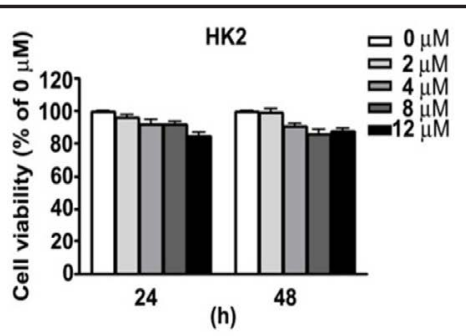

D

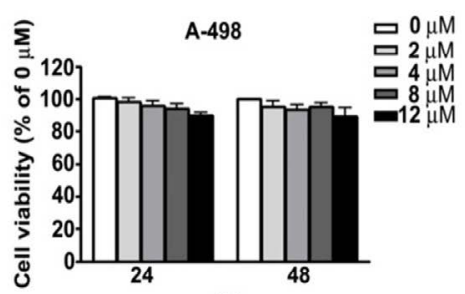

(h)

$F$

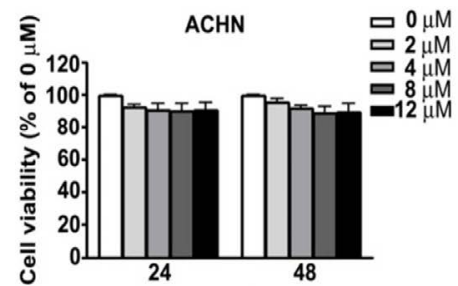

(h) 


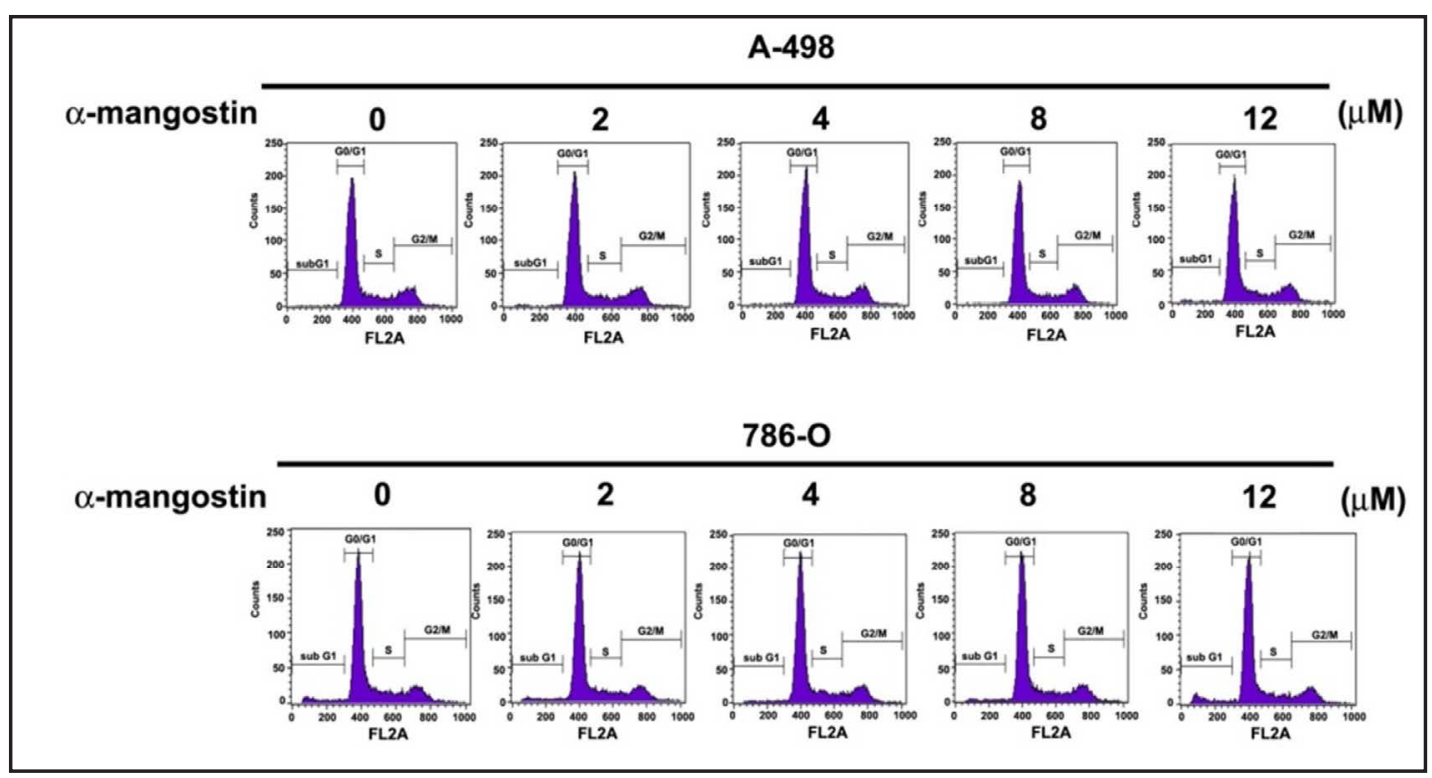

Fig. 2. Effects of $\alpha$-mangostin on cell cycle of RCC cells. A-498 and 786-0 cells were treated with various concentrations of $\alpha$-mangostin, and cell cycle distribution was measured using flow cytometry after $24 \mathrm{~h}$.

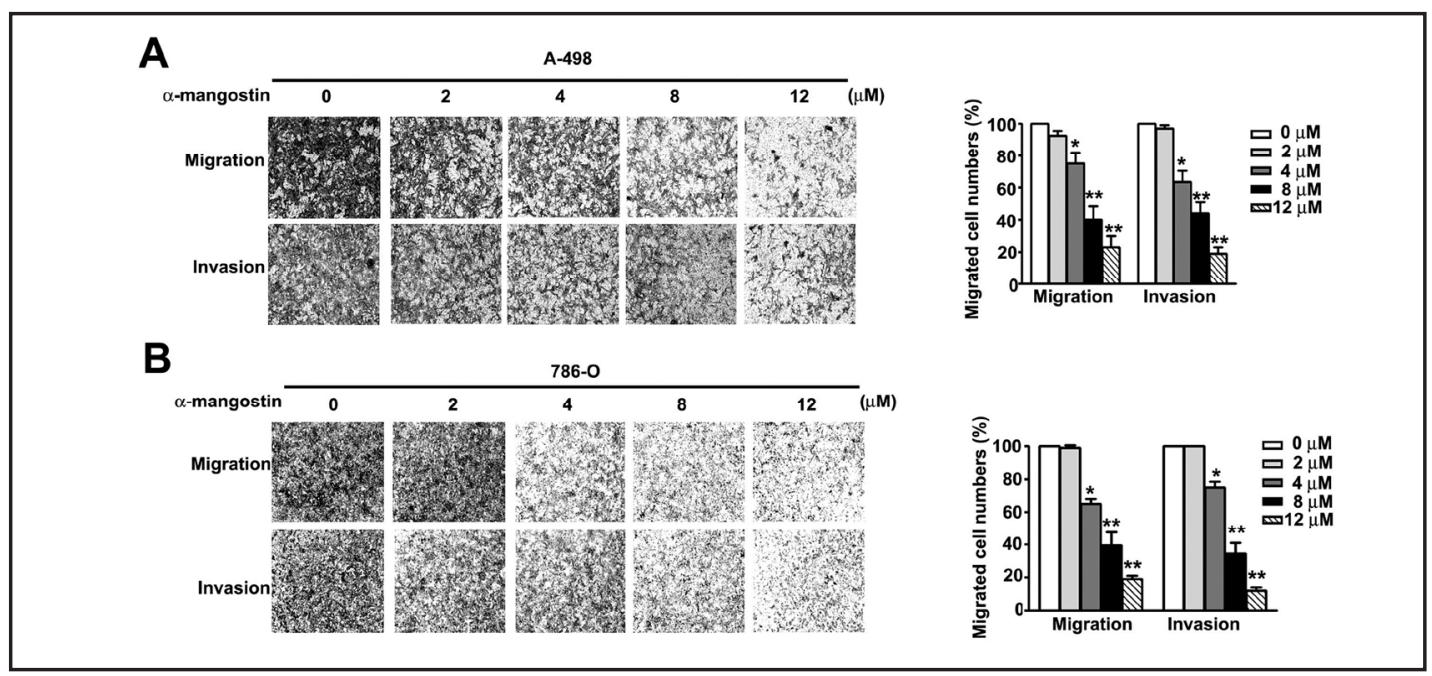

Fig. 3. Effects of $\alpha$-mangostin on migration and invasion of RCC cells. (A-B) A-498 and 786-0 cells were incubated with various concentrations of $\alpha$-mangostin for $24 \mathrm{~h}$, and migration and invasion were determined using a migration assay and the Matrigel-invasion assay. Cells in the lower surface of the Boyden chamber were stained with Giemsa stain and photographed under a light microscope at $400 \times$. Data are presented as means \pm SEs of at least three independent experiments.* indicates $\mathrm{p}<0.05$ and ${ }^{* *}$ indicates $\mathrm{p}<0.01$ compared with the untreated control $(0 \mu \mathrm{M})$.

$\alpha$-mangostin inhibits protein expression and activity of MMP-9 in RCC cells

Next, we performed western blotting and gelatin zymography of 786-0 cells to examine the effect of $\alpha$-mangostin on the protein expression and activity of MMP-9 and MMP-2, which have important roles in tumor cell migration and invasion. The results show that $\alpha$-mangostin treatment induced large concentration-dependent reductions of MMP-9 protein expression (Fig. 4A) and enzyme activity (Fig. 4B), but had no significant effect on MMP-2 expression and activity.

\section{KARGER}


A
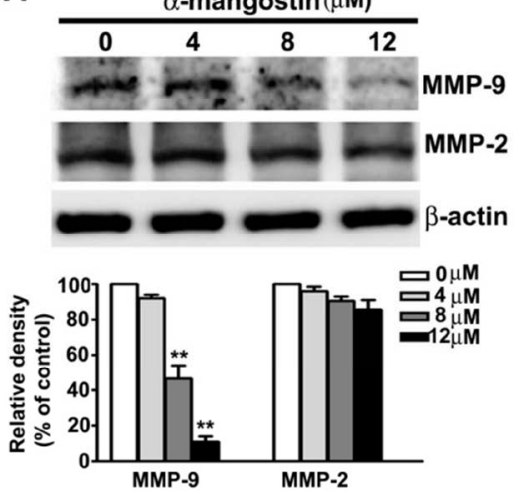

B
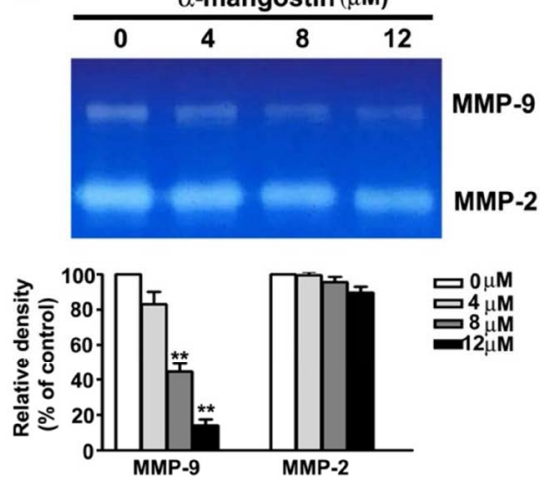

Fig. 4. Effects of $\alpha$-mangostin on expression of MMP-9 in RCC cells. 786-0 cells were incubated with various concentrations of $\alpha$-mangostin for $24 \mathrm{~h}$. (A) Total protein lysates were analyzed by western blotting to determine the expression of MMP-2 and MMP-9. (B) Conditioned media were collected and MMP-2 and MMP-9 activities were measured using gelatin zymography and quantified by densitometry. Data are presented as means \pm SEs of at least three independent experiments.* indicates $\mathrm{p}<0.05$ and ${ }^{* *}$ indicates $\mathrm{p}<0.01$ compared with the untreated control $(0 \mu \mathrm{M})$.

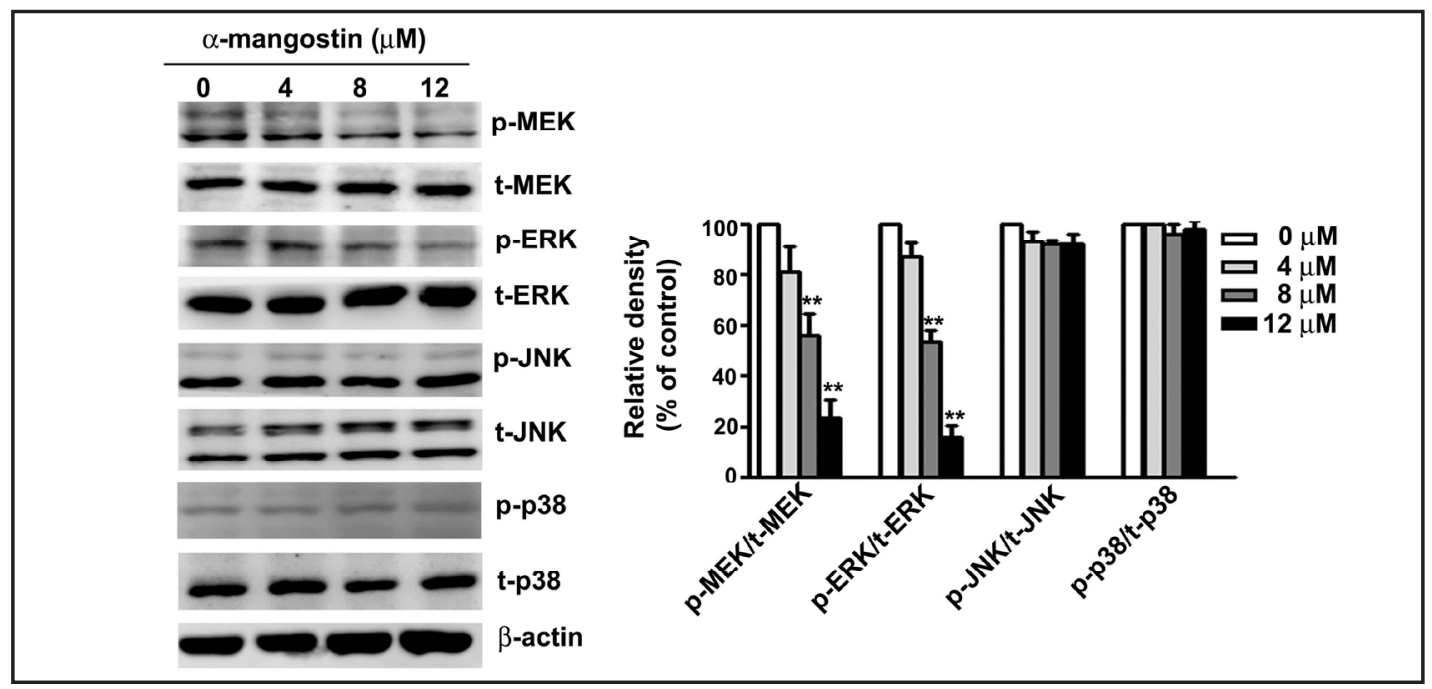

Fig. 5. Effects of $\alpha$-mangostin on MAPK signaling pathway in RCC cells. 786-0 cells were incubated with various concentrations of $\alpha$-mangostin for $24 \mathrm{~h}$, and total cell lysates were analyzed by western blotting to determine the levels of p-MEK, t-MEK, p-ERK, t-ERK, p-JNK, t-JNK, p-p38, and t-p-38. $\beta$-actin was used as internal control for protein equal loading. Data are presented as means \pm SEs of at least three independent experiments.* indicates $\mathrm{p}<0.05$ and ${ }^{* *}$ indicates $\mathrm{p}<0.01$ compared with the untreated control $(0 \mu \mathrm{M})$.

$\alpha$-mangostin inhibits cell migration and invasion via MEK/ERK-mediated MMP-9 expression

Next, we examined the signaling pathway(s) through which $\alpha$-mangostin inhibits MMP-9 expression in 786-0 cells. Treatment of 786-0 cells with various concentrations of $\alpha$-mangostin for $24 \mathrm{~h}$ indicated that this compound induced significant concentration-dependent decreases in the phosphorylation of MEK and ERK, but had no significant effect of the phosphorylation of JNK and p38 (Fig. 5). These findings suggest that $\alpha$-mangostin appears to inactivate MEK/ERK-mediated signaling pathways. 


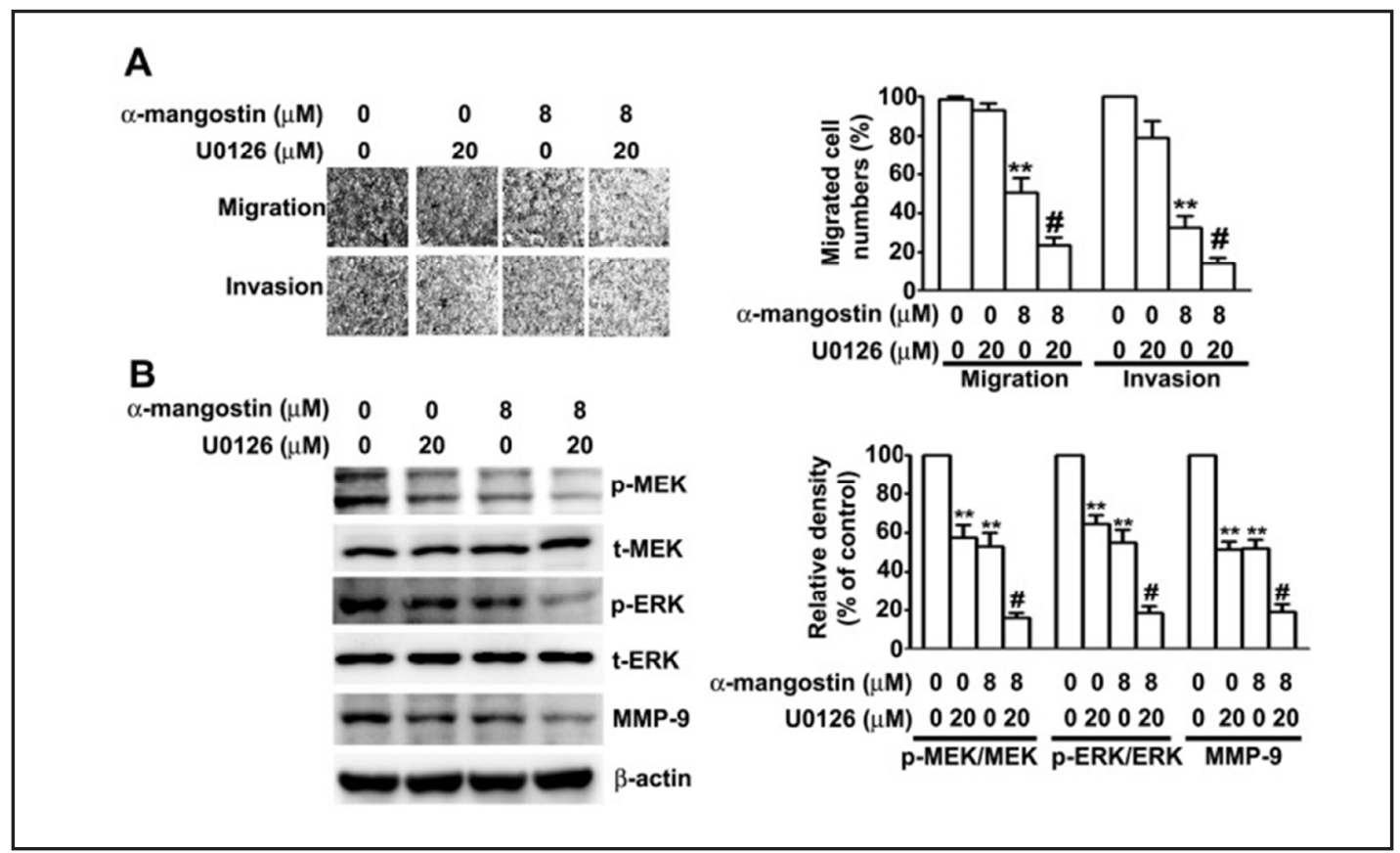

Fig. 6. Effects of $\alpha$-mangostin and a MEK inhibitor (U0126) on RCC cells. 786-0 cells were pre-treated with U0126 $(20 \mu \mathrm{M})$ for $2 \mathrm{~h}$, and then with or without $\alpha$-mangostin $(20 \mu \mathrm{M})$ for $24 \mathrm{~h}$. (A) Cells were assessed for the abilities of migration and invasion. Quantification of migration and invasion were shown as histograms chart. (B) Cell lysates were subjected to Western blotting assay to determine the expression p-MEK, t-MEK, p-ERK, t-ERK, and MMP-9 proteins. $\beta$-actin was used as internal control for protein equal loading. Data are presented as the mean $\pm \mathrm{SE}$ of at least three independent experiments. ${ }^{* *} \mathrm{P}<0.01$, compared with control, $\# \mathrm{P}<0.01$, compared with $\alpha$-mangostin treatment alone.

We further investigated the effect of $\alpha$-mangostin on migration and invasion of RCC cells through the MEK/ERK pathway. Thus, we pretreated 786-O cells with $20 \mu \mathrm{M}$ U0126 (a specific MEK inhibitor) for $2 \mathrm{~h}$, added $\alpha$-mangostin $(8 \mu \mathrm{M})$ for $24 \mathrm{~h}$, and then measured cell migration and invasion. The results indicate that treatment with $\alpha$-mangostin and U0126 led to greater inhibition of cell migration and invasion than either agent alone (Fig. 6A). Similarly, western blotting indicated that both agents suppressed the phosphorylation of MEK and ERK and expression of MMP-9 more than either agent alone (Fig. 6B). These results suggest that $\alpha$-mangostin suppresses MMP-9 expression through inhibition of the MEK/ ERK signaling pathway, and that this pathway plays a key role in the inhibition of RCC cell migration and invasion.

\section{$\alpha$-mangostin inhibits transcription of MMP-9 via MEK/ERK pathway}

We examined whether $\alpha$-mangostin treatment regulates MMP-9 expression at the transcriptional level by use of quantitative RT-PCR. The results indicate that $\alpha$-mangostin inhibited the transcription of MMP-9 in 786-0 cells (Fig. 7A), and that co-administration of $\alpha$-mangostin and U0126 suppressed the expression of MMP-9 greater than either agent alone (Fig. 7B). We also examined the effect of $\alpha$-mangostin and U0126 on the MMP-9 promoter by transfection of 786-0 cells with MMP-9 promoter-luciferase vectors. The results indicate a significant concentration-dependent attenuation of luciferase fluorescence in cells treated with $\alpha$-mangostin for $24 \mathrm{~h}$ (Fig. 7C), and that co-administration of $\alpha$-mangostin and U0126 suppressed the activity of the MMP-9 promoter more than either agent alone (Fig. 7D). Taken together, our results suggest that $\alpha$-mangostin treatment represses the MEK/ERK signaling pathway in RCC cells, and this reduces the activity of the MMP-9 promoter, thereby repressing transcription of MMP-9 and inhibiting cell invasion and migration. 
A

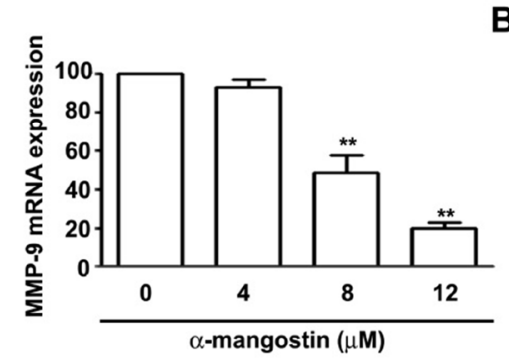

C

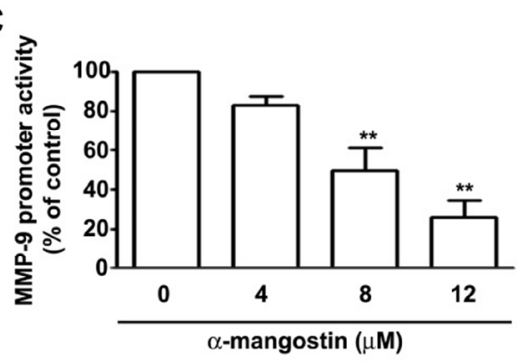

B

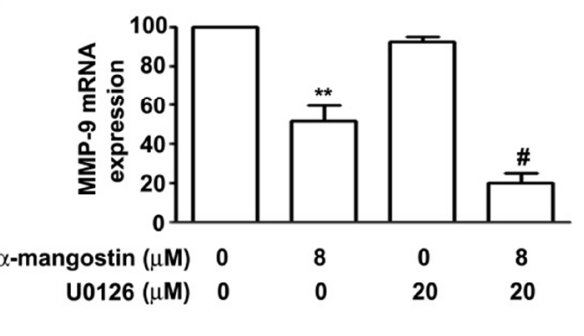

D

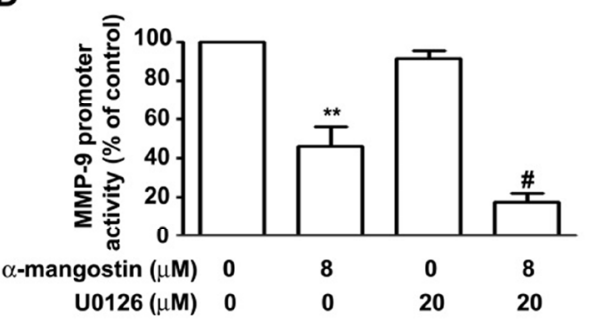

Fig. 7. Effects of $\alpha$-mangostin and a MEK inhibitor (U0126) on expression and transcriptional activity of MMP-9 in RCC cells. (A and C) 786-0 cells were incubated with various concentrations of $\alpha$-mangostin for $24 \mathrm{~h}$. Then expression of MMP-9 mRNA was determined by qRT-PCR, and the activity of the MMP-9 promoter in transfected cells was determined by a luciferase assay. (B and D) 786-0 cells were pre-treated with U0126 $(20 \mu \mathrm{M})$ for $2 \mathrm{~h}$, then incubated with or without $\alpha$-mangostin $(20 \mu \mathrm{M})$ for $24 \mathrm{~h}$. Expression of MMP-9 was determined by RT-qPCR and the activity of MMP-9 promoter in transfected cells was determined by a luciferase assay. Data are presented as the mean $\pm \mathrm{SE}$ of at least three independent experiments. ${ }^{* *} \mathrm{P}<0.01$, compared with control, $\# \mathrm{P}<0.01$, compared with $\alpha$-mangostin treatment alone.

\section{Discussion}

Over the past 15 years, treatments for RCC have evolved from traditional surgical nephrectomy with chemotherapy for localized RCC to therapies that target specific signaling pathways, such as the vascular endothelium growth factor (VEGF) pathway, and mTOR inhibitors for patients with metastatic RCC. However, because of the high cost and toxicities associated with many targeted therapies [25], and because most patients with metastasis have short survival times-even with these treatments-it is essential to identify new drugs to improve the survival times of these patients. The present in vitro study indicates that $\alpha$-mangostin inhibited the invasion and migration of RCC cells and had no evident cytotoxic effects. Our further analysis indicated that $\alpha$-mangostin reduced the expression of MMP-9 mRNA and protein, and this inhibited MEK/ERK signaling pathways in these human RCC cells.

The process of metastasis includes alteration of cell adhesion in the ECM and basement membrane, followed by degradation of ECM and basement membrane cells, detachment of cancer cells from the primary site, invasion into blood vessels and establishment of new tumors at distant sites [26]. The MMPs are a family of zinc-dependent endopeptidases that are critical in promotion of cancer cell invasion and metastasis because they digest basement membrane and ECM proteins, such as collagen, laminin, fibronectin, and proteoglycans. Several upstream signaling pathways regulate the MMPs [27]. Overexpression of several MMPs (MMP-1, MMP-2, and MMP-9) in RCC is associated with tumor stage, histological grade, progression, invasion of microvasculature, and distant metastasis [28]. MMP-9 can degrade collagen and increase the bio-availability of pro-angiogenic factors, such as VEGF and transforming growth factor (TGF)- $\beta$ [29]. Other studies reported that increased 
Fig. 8. Proposed mechanism through which $\alpha$-mangostin inhibits RCC cell migration and invasion. $\alpha$-mangostin treatment leads to phosphorylation of MEK and ERK, thereby down-regulating this pathway. This leads to reduced MMP-9 transcription, and inhibition of cancer cell migration and invasion.

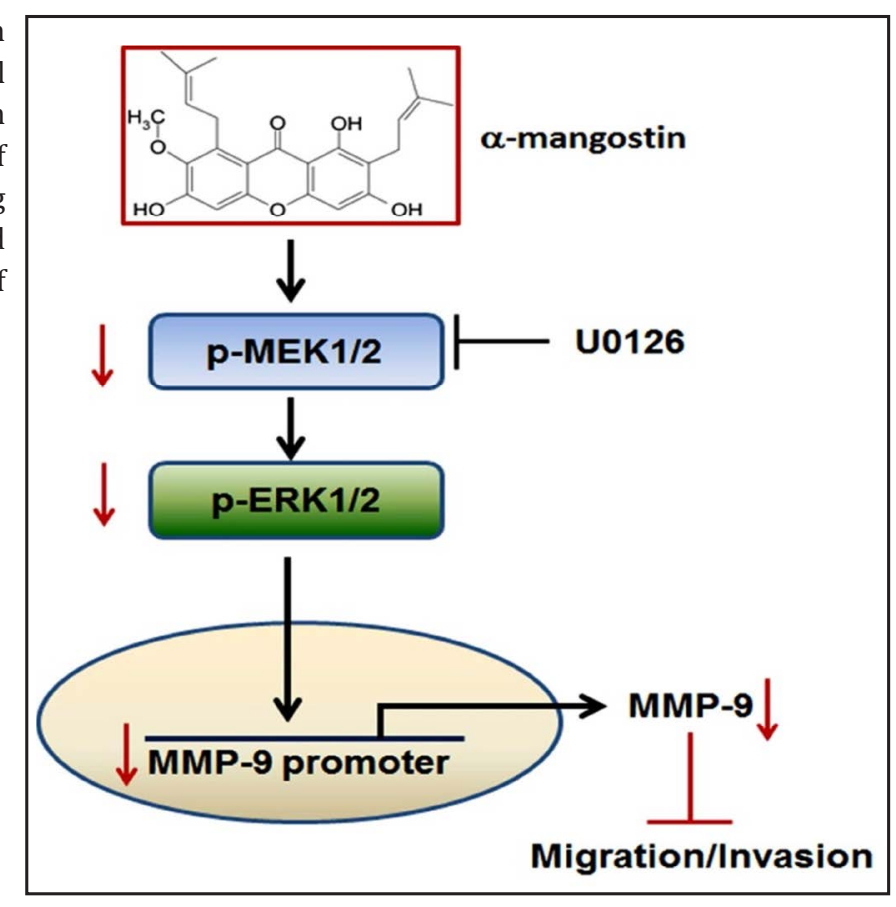

phosphorylation of ERK and enhanced expression of MMP-2 or MMP-9 by treatment with gamma-aminobutyric acid (an inhibitory neurotransmitter) or knockdown of hepatocellular carcinoma-related protein (HCRP) increased the invasive activity of RCC cells [30]. Additional evidence indicates that a pyrrole-imidazole polyamide specifically targets binding sites on the MMP-9 promoter, and thereby inhibits the invasion (but not proliferation) of RCC cells [14]. We demonstrated that $\alpha$-mangostin had inhibitory effects on the MMP-9 transcription activity and protein expression. This inhibitory effect is likely responsible for the suppressive effects of $\alpha$-mangostin on RCC cell migration and invasion.

Several signaling pathways induce MMP-9 expression, particularly the p38 MAPK, JNK, and ERK pathways [31, 32]. $\alpha$-mangostin inhibits the expression of MMP-2 and MMP-9 via inhibition of JNK phosphorylation, and thereby suppresses the migration and invasion of PC-3 prostate cancer cells [20], and it also inhibits ERK signaling pathways in HCT-116 colorectal carcinoma cells [33] and pancreatic cancer cells [34]. Similarly, epigallocatechin3 -gallate, a water-soluble flavonoid, reduces the viability, induces apoptosis, and suppresses the invasion and migration of RCC cells by down-regulation of MMP-2 and MMP-9 [35]. Melatonin also has anti-metastatic effects by reducing p65- and p52-DNA-binding and Aktmediated JNK and ERK signaling pathways, which inhibit MMP-9 transcription [36].

To the best of our knowledge, this is the first study to document the anti-metastatic effect of $\alpha$-mangostin on human RCC cells. We demonstrated that $\alpha$-mangostin inhibited RCC cell migration and invasion by decreasing the expression and activity of MMP-9, and that the $\alpha$-mangostin-induced inhibition of MMP-9 transcription was due to its suppression of the MEK/ERK pathway (Fig. 8). These findings suggest that $\alpha$-mangostin has potential as an anti-metastatic agent. Future animal studies and clinical studies of $\alpha$-mangostin are needed to assess its therapeutic efficacy against RCC.

\section{Acknowledgements}

This work was supported by grants from Buddhist Dalin Tzu Chi General Hospital (DTCRD105(2)-E-19) and Changhua Christian Hospital, Changhua, Taiwan (105-CCHIRP-027). 


\section{Cellular Physiology Cell Physiol Biochem 2017;44:1460-1470 \begin{tabular}{ll|l} 
and BiOChemistry & DOI: 10.1159/000485582 & $\begin{array}{l}\text { (c) } 2017 \text { The Author(s). Published by S. Karger AG, Basel } \\
\text { www.karger.com/cpb }\end{array}$
\end{tabular}

\section{Disclosure Statement}

The authors declare that they have no competing interests.

\section{References}

1 Znaor A, Lortet-Tieulent J, Laversanne M, Jemal A, Bray F: International variations and trends in renal cell carcinoma incidence and mortality. Eur Urol 2015;67:519-530.

-2 Yang L, Zhao Z, Zhao S, Chen C, Cong X, Li Z, Ren M: The Clinicopathological Significance of Epigenetic Silencing of VHL Promoter and Renal Cell Carcinoma: A Meta-Analysis. Cell Physiol Biochem 2016;40:14651472.

-3 Siegel R, Naishadham D, Jemal A: Cancer statistics, 2013. CA Cancer J Clin 2013;63:11-30.

4 Chiong E, Tay MH, Tan MH, Kumar S, Sim HG, Teh BT, Umbas R, Chau NM: Management of kidney cancer in Asia: resource-stratified guidelines from the Asian Oncology Summit 2012. Lancet Oncol 2012;13:e482491.

-5 Tian X, Dai S, Sun J, Jiang S, Sui C, Meng F, Li Y, Fu L, Jiang T, Wang Y, Su J, Jiang Y: Inhibition of MDM2 Re-Sensitizes Rapamycin Resistant Renal Cancer Cells via the Activation of p53. Cell Physiol Biochem 2016;39:2088-2098.

6 Silva MT, Galvao TF, Zimmerman IR, Pereira MG, Lopes LC: Non-aspirin non-steroidal anti-inflammatory drugs for the primary chemoprevention of non-gastrointestinal cancer: summary of evidence. Curr Pharm Des 2012;18:4047-4070.

-7 Hsieh YH, Lee CH, Chen HY, Hsieh SC, Lin CL, Tsai JP: Induction of cell cycle arrest, DNA damage, and apoptosis by nimbolide in human renal cell carcinoma cells. Tumour Biol 2015;36:7539-7547.

8 Wang F, Ma H, Liu Z, Huang W, Xu X, Zhang X: alpha-Mangostin inhibits DMBA/TPA-induced skin cancer through inhibiting inflammation and promoting autophagy and apoptosis by regulating PI3K/Akt/mTOR signaling pathway in mice. Biomed Pharmacother 2017;92:672-680.

-9 Le TT, Pandey RP, Gurung RB, Dhakal D, Sohng JK: Efficient enzymatic systems for synthesis of novel alphamangostin glycosides exhibiting antibacterial activity against Gram-positive bacteria. Appl Microbiol Biotechnol 2014;98:8527-8538.

10 Kurose H, Shibata MA, Iinuma M, Otsuki Y: Alterations in cell cycle and induction of apoptotic cell death in breast cancer cells treated with $\alpha$-mangostin extracted from mangosteen pericarp. J Biomed Biotechnol 2012;2012:672428.

11 Li G, Petiwala SM, Nonn L, Johnson JJ: Inhibition of CHOP accentuates the apoptotic effect of alphamangostin from the mangosteen fruit (Garcinia mangostana) in 22Rv1 prostate cancer cells. Biochem Biophys Res Commun 2014;453:75-80.

12 Shan T, Cui XJ, Li W, Lin WR, Lu HW, Li YM, Chen X, Wu T: alpha-Mangostin suppresses human gastric adenocarcinoma cells in vitro via blockade of Stat3 signaling pathway. Acta Pharmacol Sin 2014;35:10651073.

13 Yamaguchi N, Osaki M, Onuma K, Yumioka T, Iwamoto H, Sejima T, Kugoh H, Takenaka A, Okada F: Identification of MicroRNAs Involved in Resistance to Sunitinib in Renal Cell Carcinoma Cells. Anticancer Res 2017;37:2985-2992.

14 Sato A, Nagase H, Obinata D, Fujiwara K, Fukuda N, Soma M, Yamaguchi K, Kawata N, Takahashi S: Inhibition of MMP-9 using a pyrrole-imidazole polyamide reduces cell invasion in renal cell carcinoma. Int J Oncol 2013;43:1441-1446.

15 Campbell L, Nuttall R, Griffiths D, Gumbleton M: Activated extracellular signal-regulated kinase is an independent prognostic factor in clinically confined renal cell carcinoma. Cancer 2009;115:3457-3467.

16 Cho NH, Shim HS, Rha SY, Kang SH, Hong SH, Choi YD, Hong SJ, Cho SH: Increased expression of matrix metalloproteinase 9 correlates with poor prognostic variables in renal cell carcinoma. Eur Urol 2003;44:560-566.

17 Yang SF, Lee WJ, Tan P, Tang CH, Hsiao M, Hsieh FK, Chien MH: Upregulation of miR-328 and inhibition of CREB-DNA-binding activity are critical for resveratrol-mediated suppression of matrix metalloproteinase-2 and subsequent metastatic ability in human osteosarcomas. Oncotarget 2015;6:2736-2753. 


\section{Cellular Physiology Cell Physiol Biochem 2017;44:1460-1470 \begin{tabular}{ll|l} 
DOI: 10.1159/000485582 & $\begin{array}{l}\text { O 2017 The Author(s). Published by S. Karger AG, Basel } \\
\text { www.karger.com/cpb }\end{array}$
\end{tabular}

18 Selim KA, Abdelrasoul H, Aboelmagd M, Tawila AM: The Role of the MAPK Signaling, Topoisomerase and Dietary Bioactives in Controlling Cancer Incidence. Diseases 2017;5.

19 Shih YW, Chien ST, Chen PS, Lee JH, Wu SH, Yin LT: Alpha-mangostin suppresses phorbol 12-myristate 13-acetate-induced MMP-2/MMP-9 expressions via alphavbeta3 integrin/FAK/ERK and NF-kappaB signaling pathway in human lung adenocarcinoma A549 cells. Cell Biochem Biophys 2010;58:31-44.

20 Hung SH, Shen KH, Wu CH, Liu CL, Shih YW: Alpha-mangostin suppresses PC-3 human prostate carcinoma cell metastasis by inhibiting matrix metalloproteinase-2/9 and urokinase-plasminogen expression through the JNK signaling pathway. J Agric Food Chem 2009;57:1291-1298.

-21 Lee YB, Ko KC, Shi MD, Liao YC, Chiang TA, Wu PF, Shih YX, Shih YW: alpha-Mangostin, a novel dietary xanthone, suppresses TPA-mediated MMP-2 and MMP-9 expressions through the ERK signaling pathway in MCF-7 human breast adenocarcinoma cells. J Food Sci 2010;75:H13-23.

22 Wang R, Ke ZF, Wang F, Zhang WH, Wang YF, Li SH, Wang LT: GOLPH3 overexpression is closely correlated with poor prognosis in human non-small cell lung cancer and mediates its metastasis through upregulating MMP-2 and MMP-9. Cell Physiol Biochem 2015;35:969-982.

23 Hung TW, Tsai JP, Lin SH, Lee CH, Hsieh YH, Chang HR: Pentraxin 3 Activates JNK Signaling and Regulates the Epithelial-To-Mesenchymal Transition in Renal Fibrosis. Cell Physiol Biochem 2016;40:1029-1038.

24 Cheng HL, Hsieh MJ, Yang JS, Lin CW, Lue KH, Lu KH, Yang SF: Nobiletin inhibits human osteosarcoma cells metastasis by blocking ERK and JNK-mediated MMPs expression. Oncotarget 2016;7:35208-35223.

25 Heng DY: The next 10 years: Challenges for the future and overcoming resistance to targeted therapies for renal cell carcinoma. Can Urol Assoc J 2010;10:S256-S258.

26 Vincent CT, Fuxe J: EMT, inflammation and metastasis. Semin Cancer Biol. 2017.

27 Engbring JA, Kleinman HK : The basement membrane matrix in malignancy. J Pathol 2003;200:465-470.

-28 Abdel-Wahed MM, Asaad NY, Aleskandarany M: Expression of matrix metalloproteinase-2 in renal cell carcinoma. J Egypt Natl Canc Inst 2004;16:168-177.

29 Colak S, Ten Dijke P: Targeting TGF-beta Signaling in Cancer. Trends Cancer 2017;3:56-71.

-30 Inamoto T, Azuma H, Sakamoto T, Kiyama S, Ubai T, Kotake Y, Watanabe M, Katsuoka Y: Invasive ability of human renal cell carcinoma cell line Caki-2 is accelerated by gamma-aminobutyric acid, via sustained activation of ERK1/2 inducible matrix metalloproteinases. Cancer Invest 2007;25:574-583.

31 Chao W, Deng JS, Huang SS, Li PY, Liang YC, Huang GJ: 3, 4-dihydroxybenzalacetone attenuates lipopolysaccharide-induced inflammation in acute lung injury via down-regulation of MMP-2 and MMP-9 activities through suppressing ROS-mediated MAPK and PI3K/AKT signaling pathways. Int Immunopharmacol 2017;50:77-86.

-32 Lee SJ, Cho SC, Lee EJ, Kim S, Lee SB, Lim JH, Choi YH, Kim WJ, Moon SK : Interleukin-20 promotes migration of bladder cancer cells through extracellular signal-regulated kinase (ERK)-mediated MMP-9 protein expression leading to nuclear factor (NF-kappaB) activation by inducing the up-regulation of p21(WAF1) protein expression. J Biol Chem 2013;288:5539-5552.

-33 Aisha AF, Abu-Salah KM, Ismail Z, Majid AM. In vitro and in vivo anti-colon cancer effects of Garcinia mangostana xanthones extract. BMC Complement Altern Med 2012;12:104.

-34 Yuan J, Wu Y, Lu G: alpha-Mangostin suppresses lipopolysaccharide-induced invasion by inhibiting matrix metalloproteinase-2/9 and increasing E-cadherin expression through extracellular signal-regulated kinase signaling in pancreatic cancer cells. Oncol Lett 2013;5:1958-1964.

35 Chen SJ, Yao XD, Peng BO, Xu YF, Wang GC, Huang J, Liu M, Zheng JH : Epigallocatechin-3-gallate inhibits migration and invasion of human renal carcinoma cells by downregulating matrix metalloproteinase- 2 and matrix metalloproteinase-9. Exp Ther Med 2016;11:1243-1248.

-36 Lin YW, Lee LM, Lee WJ, Chu CY, Tan P, Yang YC, Chen WY, Yang SF, Hsiao M, Chien MH : Melatonin inhibits MMP-9 transactivation and renal cell carcinoma metastasis by suppressing Akt-MAPKs pathway and NFkappaB DNA-binding activity. J Pineal Res 2016;60:277-290. 